\title{
A TUTELA PROVISÓRIA COMO PROTETORA DO DIREITO FUNDAMENTAL A UM MEIO AMBIENTE EQUILIBRADO: O CASO DAS TERRAS ÍNDIGENAS YANOMAMI E MUNDURUKU (ADPF 709/DF)
}

\author{
José Henrique Mouta Araújo* \\ Jacob Arnaldo Campos Farache** \\ Victória Vasconcelos Sá***
}

\begin{abstract}
RESUMO
O presente artigo expõe como o instituto da tutela provisória pode ser utilizado como um instrumento de proteção de um direito fundamental a um meio ambiente equilibrado. Nesse intuito, será analisado um caso concreto: a decisão liminar proferida no julgamento da ADPF 709/DF, a qual determinou a retirada imediata de invasores das terras indígenas Yanomami e Munduruku na Amazônia brasileira. A pesquisa, ora desenvolvida, tem caráter teórico-descritivo e viés qualitativo, que é proposta dentro de uma perspectiva crítica e reflexiva. Utiliza-se o método dedutivo, de procedimento histórico-comparativo e a técnica de pesquisa bibliográfica especializada no assunto pesquisado.
\end{abstract}

Palavras-chave: Tutela Provisória. Direitos Fundamentais. Meio Ambiente Equilibrado. Terras Indígenas. Supremo Tribunal Federal.

\section{PROVISIONAL GUARDIANSHIP AS PROTECTOR OF FUNDAMENTAL RIGHTS TO A BALANCED ENVIRONMENT: THE CASE OF THE YANOMAMI AND MUNDURUKU INDIGENOUS LANDS (ADPF 709 / DF)}


analyzed: the preliminary injunction rendered in the judgment of ADPF 709/DF, which determined the immediate removal of invaders from the Yanomami and Munduruku indigenous lands in the Brazilian Amazon. The research developed, has a theoreticaldescriptive character and a qualitative bias, which is proposed within a critical and reflective perspective. It uses the deductive method, historical-comparative procedure and the technique of bibliographic research specialized in the researched subject.

Keywords: Provisional Guardianship. Fundamental rights. Balanced Environment. Indigenous Lands. Federal Court of Justice.

\section{INTRODUÇÃO}

A questão ambiental envolve diversas variáveis: políticas públicas, aspectos sociais, desenvolvimento econômico, desigualdade econômica, proteção ao meio ambiente etc.

Recentemente, diversos estudos apontam para um momento crítico do meio ambiente no território amazônico. Cite-se, por exemplo, que houve: a) o aumento do desmatamento ilegal na Amazônia Legal em aproximadamente 216\% (IMAZON, 2021); b) a possibilidade de expansão de projetos de mineração, de exploração de energia e portuários (CASTRO, 2019); e, c) a expansão agropecuária em áreas da floresta amazônica (WALKER, 2009).

Certamente, o meio ambiente é um tema que desperta constantemente a opinião pública. No mundo acadêmico, não é diferente. O histórico conflito entre interesses econômicos e o meio ambiente, geralmente, enseja argumentos dos mais diversos. Esta situação só se agravou durante o período de pandemia de COVID-19, pois tanto a fiscalização do Poder Público ficou mais escassa quanto a presença de eventuais invasores criou uma nova variável: o favorecimento do contágio do vírus em decorrência do contato de povos nativos com pessoas contaminadas externas à comunidade indígena (MOUTA, 2021).

Geralmente, este conflito de ideias e políticas públicas é levado à apreciação pelo Poder Judiciário, a fim de que este indique o caminho a ser seguido pelos atores sociais. Este é o caso da Arguição de Descumprimento de Preceito Fundamental (ADPF) n ${ }^{\circ} 709$, na qual se discute a presença de invasores em terras indígenas Yanomami e Munduruku, os quais estariam promovendo "ataques a tiros a indígenas, mortes, desnutrição, anemia, 
contágio por mercúrio, desmatamento e garimpo ilegal”, justamente, durante o período de pandemia de COVID-19 (SECCHI, 2016).

Importante destacar que Secchi (2016, p. 02) define política pública como sendo: "uma diretriz elaborada para enfrentar um problema público".

Não obstante, é cediço que o processo judicial é algo que toma um certo tempo do aparato judicial para chegar a uma decisão final sobre uma determinada questão. Sem adentrar em questões acerca da eficiência do aparato judicial (JORGE NETO, 2018), é inegável que certas demandas ambientais que são judicializadas não podem se dar ao luxo de aguardar todo o trâmite processual para serem solucionadas, sob pena de perderem totalmente sua utilidade. Este, aparentemente, é o caso da ADPF n ${ }^{\circ}$ 709/DF (BRASIL, 2021).

No curso do presente artigo, tentar-se-á mostrar a relevância do instrumento da tutela provisória, analisando o caso da ADPF n ${ }^{\circ}$ 709/DF, justamente, como exemplo de que medidas urgentes são necessárias para proteção efetiva de um meio ambiente equilibrado no cenário amazônico, não se podendo aguardar o completo deslinde da causa para se obter a tutela jurisdicional pleiteada em juízo (BRASIL, 2021).

Nesse sentido, o problema proposto é: analisar se os requisitos (em especial, o da probabilidade do direito) pode ser mitigado para concessão de eventual tutela provisória em demandas envolvendo a proteção do meio ambiente, em especial, pela presença dos princípios da precaução e prevenção norteadores do Direito Ambiental?

A base teórica será a doutrina de processo civil e a ambientalista brasileira, agregando a estes autores alguns pesquisadores locais, justamente, para se realizar uma contextualização da teoria mais abrangente com as especificidades da realidade amazônica, reiterando a necessidade de uma proteção ambiental célere para assegurar uma proteção efetiva do meio ambiente.

Por fim, para atender ao problema proposto, este artigo dividir-se-á, além da presente introdução, em três capítulos, quais sejam: a) as tutelas provisórias no CPC: conceito e requisitos; b) o direito fundamental a um meio ambiente equilibrado e a relevância dos princípios da precaução e prevenção na seara ambiental; e, c) uma breve análise da liminar concedida na ADPF no 709/DF e seus efeitos práticos para proteção do meio ambiente nas terras indígenas Yanomami e Munduruku na Amazônia brasileira. Por 
fim, serão feitas considerações finais para verificar se o problema proposto pode ou não ser respondido ao longo do texto.

\section{AS TUTELAS PROVISÓRIAS NO CPC: CONCEITO E REQUISITOS}

Certamente, um tema que sofreu profundas modificações com o advento do CPC de 2015 foi o das tutelas provisórias.

Inicialmente, cabe expor que a tutela jurisdicional oferecida pelo Estado-juiz estrutural pode ser definida em definitiva e cautelar. A primeira, por sua vez, compreende a satisfativa e a não-satisfativa. A segunda, porém, não visa satisfazer o direito propriamente dito, mas proteger sua futura satisfação, protegendo-o (DIDIER JR.; BRAGA; OLIVEIRA, 2015).

Deveras, o Estado-juiz não entrega a tutela definitiva sem um certo lapso temporal. O tempo é necessário para formação do convencimento do magistrado, bem como para a produção de provas, para o exercício do contraditório etc. Enfim, uma decisão definitiva exige, no mínimo, uma certa tramitação processual apta a torná-la, desde que não haja a interposição de recursos, imutável.

No entanto, este mesmo lapso temporal não se exige para a aplicação do instituto da tutela provisória. Na realidade, a tutela provisória é uma nova roupagem para institutos jurídicos processuais que já previam que muitos direitos perder-se-iam se não fossem concedidos antes do término do processo, vez que visavam garantir o resultado útil do processo ao seu término, ou seja, sua própria efetividade.

Durante a tramitação do anteprojeto do novo CPC, propunha-se que a matéria receberia o título de "tutela de urgência e tutela da evidência" entre os artigos 269 e 286. Posteriormente, a Câmara dos Deputados fez algumas alterações, modificando a matéria para o título de "tutelas provisórias" previsto entre os artigos 294 a 311 (BRASIL, 2015).

Analisando o instituto das "tutelas provisórias" propriamente dito, tem-se que a tutela de urgência pode ser de natureza cautelar ou satisfativa. A primeira antecipa "os efeitos de tutela definitiva não-satisfativa (cautelar), conferindo eficácia imediata ao direito à cautela". A segunda, por sua vez, atrai a própria tutela definitiva satisfativa, possibilitando os efeitos imediatos do direito afirmado em juízo (DIDIER JR.; BRAGA; OLIVEIRA, 2015, p. 569). 
Ambas, tanto a cautelar quanto a satisfativa, podem ser antecedentes, ou seja, concedidas no início do processo ou incidentes, as que são concedidas ao longo do trâmite processual.

Por conseguinte, existe também a tutela de evidência, espécie de tutela provisória tal qual a tutela de urgência, com previsão específica no artigo 311, do CPC, existindo quatro espécies desta, quais sejam: a) a tutela provisória de evidência punitiva (artigo 311, inciso I, do CPC), vez que pressupõe que o réu tenha praticado atos para embaraçar o andamento do processo; b) as tutelas provisórias de evidência satisfativas (artigo 311, inciso II e III, do CPC), pois ali se encontram evidências robustas para autorizar tal medida antes da oitiva da parte ré; e, c) a tutela de evidência com fulcro na insuficiência da contraprova do réu (artigo 311, inciso IV, do CPC) (DIDIER JR.; BRAGA; OLIVEIRA, 2015).

A distinção entre as tutelas de evidência e as de urgência diz respeito a que estes demandam ainda a existência de dois requisitos, sendo que apenas um deles é dispensado por aquela, qual seja: o perigo de dano ou risco ao resultado útil do processo (artigo 311, caput, do CPC) (DIDIER JR.; BRAGA; OLIVEIRA, 2015, p. 569). Sistematicamente, nasceu, assim, o sistema de Tutelas Provisórias do CPC de 2015, o qual pode ser graficamente (visual law) assim representado:

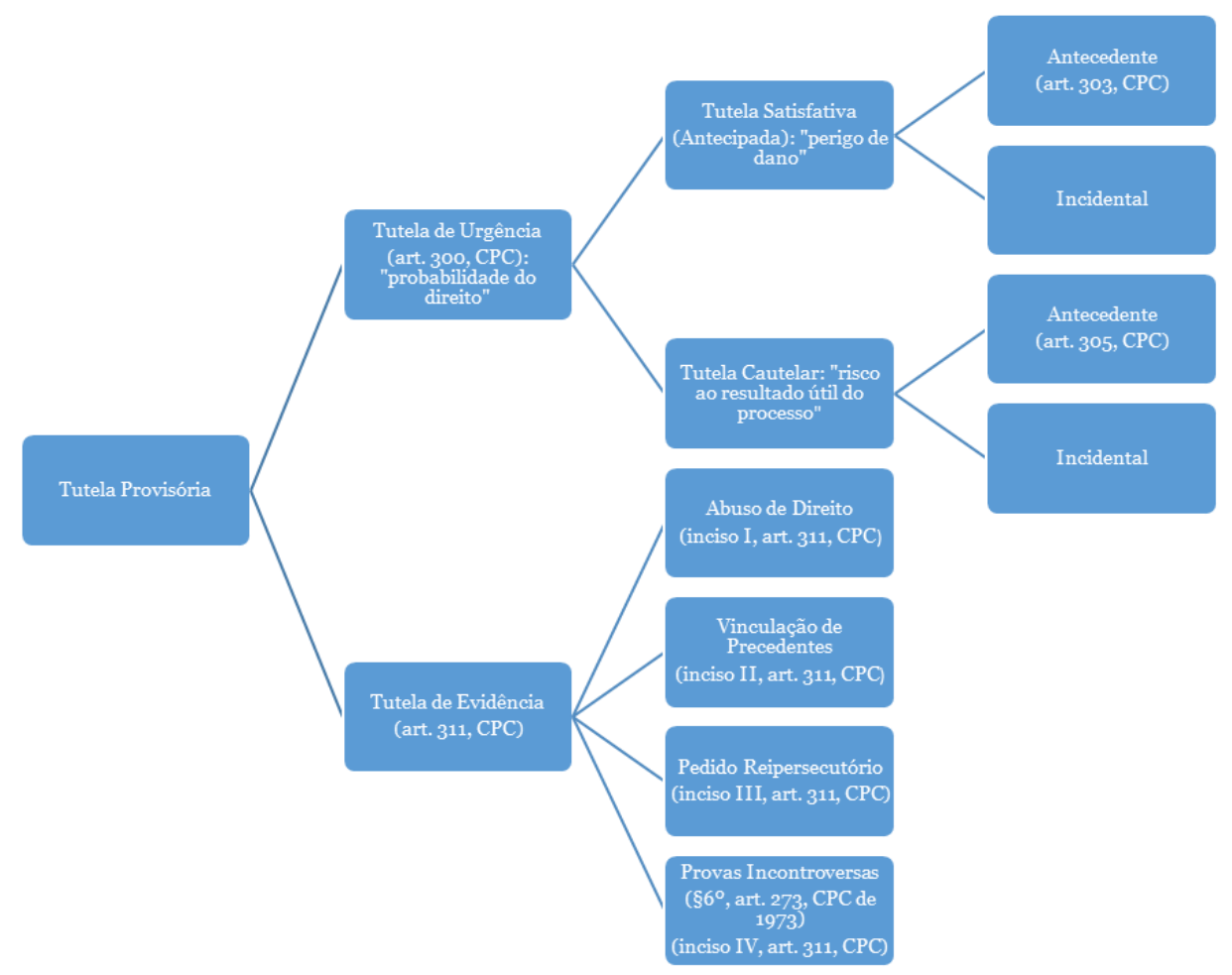


Fonte: próprio autores

Cabe, então, analisar os requisitos para concessão de uma tutela provisória: a) a probabilidade do direito (fumus boni iuris) e o perigo de dano ou o risco ao resultado útil do processo (periculum in mora).

Por fumus boni iuris, Theodoro Júnior (2016, p. 620-621) entende:

\begin{abstract}
Para a tutela de urgência, não é preciso demonstrar-se cabalmente a existência do direito material em risco, mesmo porque esse, frequentemente, é litigioso e só terá sua comprovação e declaração no final do processo. Para merecer a tutela cautelar, o direito em risco há de revelar-se apenas como o interesse que justifica o "direito de ação", ou seja, o direito ao processo de mérito.

$[\ldots]$

Incertezas ou imprecisões a respeito do direito material do requerente não podem assumir a força de impedir-lhe o acesso à tutela de urgência. Se, à primeira vista, conta a parte com a possibilidade de exercer o direito de ação e se o fato narrado, em tese, lhe assegura provimento de mérito favorável, e se acha apoiado em elementos de convencimento razoáveis, presente se acha o fumus boni iuris, em grau suficiente para autorizar a proteção das medidas sumárias.
\end{abstract}

Já o termo periculum in mora, é entendido como o fundado receio de que, enquanto aguarda a tutela definitiva, tornem-se ausentes as circunstâncias de fato favoráveis à própria tutela jurisdicional. Isto pode ocorrer, por exemplo, quando houver "risco de perecimento, destruição, desvio, deterioração, ou de qualquer mutação das pessoas, bens ou provas necessárias para a perfeita e eficaz atuação do provimento final do processo" (THEODORO JR., 2016, p. 621).

Há, ainda, um terceiro requisito da tutela provisória que já encontrava previsto no CPC de 1973 e foi repetido no vigente: a reversibilidade da medida. " $\$ 3^{\circ}$. A tutela de urgência de natureza antecipada não será concedida quando houver perigo de irreversibilidade dos efeitos da decisão" (artigo 300, $\S 3^{\circ}$, do CPC/2015).

É preciso, então, notar que existe uma vedação à concessão de tutelas provisórias de urgência de natureza satisfativa irreversíveis, pois estas significariam que decisão provisória produziria efeitos definitivos. No entanto, há casos de conhecidos como de irreversibilidade recíproca, ou seja, hipóteses "em que o juiz verifica que a concessão da medida produziria efeitos irreversíveis, mas sua denegação também teria efeitos irreversíveis. É o que se dá, por exemplo, no caso da fixação dos alimentos provisórios" (CÂMARA, 2015, p. 159). 
Didier Jr., Braga e Oliveira (2015) expõe que a finalidade da tutela provisória (gênero) é abrandar os males do tempo e garantir a efetividade da jurisdição. Do mesmo modo, Marinoni, Arenhart e Mitidiero (2017, p. 134) expõe que tal instituto visa "uma adequada distribuição do ônus do tempo no processo e a percepção de que a técnica processual só tem sentido se vista na perspectiva da tutela dos direitos são imprescindíveis para que administração da justiça civil consiga obter seus fins de forma idônea".

Em síntese, a tutela provisória é uma ferramenta que vai ao encontro do que Dinamarco (2020) intitula de um processo civil de resultados, ou seja, o processo só tem valor se atingir resultados pacificadores que efetivamente permitam o acesso à justiça. Enfim, é esta proteção que tanto anseia muitas demandas levadas diariamente ao Poder Judiciário $^{1}$ dentre estas destacam-se a de cunho ambiental por suas características específicas, conforme será analisado no tópico seguinte.

\title{
3 O DIREITO FUNDAMENTAL A UM MEIO AMBIENTE EQUILIBRADO E A RELEVÂNCIA DOS PRINCÍPIOS DA PRECAUÇÃO E PREVENÇÃO NA SEARA AMBIENTAL
}

Inicialmente, cabe expor que o meio ambiente é único, porém, para fins didáticos, ele costuma ser dividido doutrinariamente em quatro: natural, cultural, artificial e do trabalho. Do mesmo modo, é classificação adotada pelo Supremo Tribunal Federal (STF), como pode-se notar no seguinte julgado:

\begin{abstract}
A incolumidade do meio ambiente não pode ser comprometida por interesses empresariais nem ficar dependente de motivações de índole meramente econômica, ainda mais se se tiver presente que a atividade econômica, considerada a disciplina constitucional que a rege, está subordinada, dentre outros princípios gerais, àquele que privilegia a "defesa do meio ambiente" $(\mathrm{CF}$, art. 170, VI), que traduz conceito amplo e abrangente das noções de meio ambiente natural, de meio ambiente cultural, de meio ambiente artificial (espaço urbano) e de meio ambiente laboral" (BRASIL, 2006). (grifos nossos)
\end{abstract}

Analisando cada espécie do conceito de meio ambiente acima, tem-se o natural, no qual se compreende a flora, “a fauna, a atmosfera, água, solo, subsolo, os elementos da

\footnotetext{
${ }^{1}$ Sobre a judicialização da saúde durante a pandemia, é possível enumerar diversas demandas relevantes: ADIs no 6363, 6341, 6387, 6389, 6388 e 6390; ADPF nº 676; Ação Civil Originária no 3376, HC no 570.728/SP, MS 26.024
} 
biosfera, bem como recurso minerais. Enfim, toda forma e vida é considerada integrante do meio ambiente" natural (TRENNEPOHL, 2019, p. 32).

Já o meio ambiente cultural pode ser definido como:

Os elementos referentes à formação dos grupos nacionais de expressão, criações artísticas, tecnológicas, obras, objetos, documentos, edificações em sentido amplo, conjuntos urbanos, paisagísticos, arqueológicos, paleontológicos, ecológicos e científicos.

$[\ldots]$

Merecem encaixe, nesse contexto cultural, atividades como a música, as religiões, a literatura, o teatro, a dança, entre tantas outras manifestações culturais existentes. (2019, p. 33-34).

O próprio texto constitucional aborda o meio ambiente cultural em seu texto, mais especificamente, no artigo 216 quando expressamente apresenta o termo: "patrimônio cultural brasileiro" como sendo os "bens de natureza material e imaterial, tomados individualmente ou em conjunto, portadores de referência à identidade, à ação, à memória dos diferentes grupos formadores da sociedade brasileira" (BRASIL, 1988).

Posteriormente, reforçando a característica analítica de nossa Carta Magna, este mesmo dispositivo enumera, exemplificativamente, alguns destes ambientes: "os conjuntos urbanos e sítios de valor histórico, paisagístico, artístico, arqueológico, paleontológico, ecológico e científico" (BRASIL, 1988).

Nesse conceito, vale destacar que estão inseridas as culturas indígenas e dentre estas se encontram as Yanomami e as Mundurucu, que são justamente o objeto da ADPF $n^{\circ}$ 709/DF, ou seja, a proteção também desse meio ambiente cultural (BRASIL, 2021).

Doravante, existe o que se convencionou chamar de meio ambiente artificial, o qual é extraído pela doutrina do artigo 182, da Carta Magna:

Art. 182. A política de desenvolvimento urbano, executada pelo Poder Público municipal, conforme diretrizes gerais fixadas em lei, tem por objetivo ordenar o pleno desenvolvimento das funções sociais da cidade e garantir o bem-estar de seus habitantes.

$\S 1^{\circ} \mathrm{O}$ plano diretor, aprovado pela Câmara Municipal, obrigatório para cidades com mais de vinte mil habitantes, é o instrumento básico da política de desenvolvimento e de expansão urbana.

$\S 2^{\circ}$ A propriedade urbana cumpre sua função social quando atende às exigências fundamentais de ordenação da cidade expressas no plano diretor.

$\S 3^{\circ}$ As desapropriações de imóveis urbanos serão feitas com prévia e justa indenização em dinheiro.

$\S 4^{\circ}$ É facultado ao Poder Público municipal, mediante lei específica para área incluída no plano diretor, exigir, nos termos da lei federal, do proprietário do solo urbano não edificado, subutilizado ou não utilizado, que promova seu adequado aproveitamento, sob pena, sucessivamente, de: 
I - parcelamento ou edificação compulsórios;

II - imposto sobre a propriedade predial e territorial urbana progressivo no tempo; III - desapropriação com pagamento mediante títulos da dívida pública de emissão previamente aprovada pelo Senado Federal, com prazo de resgate de até dez anos, em parcelas anuais, iguais e sucessivas, assegurados o valor real da indenização e os juros legais (BRASIL, 1988).

Extrai-se deste dispositivo, o que também fora detalhado na Lei $\mathrm{n}^{\circ} 10.257 / 2001$, ou seja, o Estatuto da Cidade, onde se detalha a política urbana para as cidades brasileiras (BRASIL, 2001).

Em suma, a doutrina sintetiza o conceito de meio ambiente artificial como o espaço urbano que foi construído pelo homem (TRENNEPOHL, 2019).

Ao cabo, tem-se a classificação doutrinária do chamado meio ambiente do trabalho, o qual também possui previsão na Constituição de 1988, mais especificamente, no artigo 200: “Art. 200. Ao sistema único de saúde compete, além de outras atribuições, nos termos da lei:[...]" (BRASIL, 1988).

Nesta espécie de meio ambiente, são muito presentes os estudos ligados ao ramo especializado do Direito do Trabalho, sobretudo, porque este estuda a segurança da pessoa humana no seu local de trabalho (TRENNEPOHL, 2019, p. 37).

Atualmente, a preocupação com o meio ambiente só tem se acentuado. Diversas são as denúncias de desmatamento ilegal e predatório da floresta amazônica, de tráfico de animas silvestres, de queimadas para ampliação de áreas de plantios etc. Em outras regiões do Brasil, também diversas são as preocupações com os demais biomas brasileiros, sobretudo, com o alerta oriundo de recentes acidentes ambientais de proporções gigantescas. $^{2}$

No entanto, com a devida vênia aos órgãos de fiscalização, por questões óbvias, a tarefa de proteger a Amazônia é hercúlea por diversos motivos: extensão da floresta, dificuldade de acesso à diversas áreas, densidade populacional pequena, o modal de transporte típico da região é naturalmente lento (embarcações); etc. ${ }^{3}$

Em que pese a necessidade de fiscalização constante da Amazônia pelo governo brasileiro, sobretudo, por tudo que ela significa e representa, não se pode esquecer que

\footnotetext{
${ }^{2}$ Vide os rompimentos das barragens de Mariana (2015) e Brumadinho (2019).

${ }^{3}$ Sobre o assunto, no ano de 2020, iniciou-se uma atuação diferente pelos órgãos de fiscalização, que teve o auxílio das Forças Armadas. Tal política pública federal alegava que seu objetivo era o combate mais incisivo aos crimes ambientais e ao desmatamento ilegal na Amazônia. A operação foi chamada "Verde Brasil" e teve a coordenação do então vice-presidente da República, General Hamilton Mourão. Houve duas edições dessa operação, já tendo sido encerrada pelo governo federal (BRASIL, 2019).
} 
qualquer tentativa de se proteger a floresta não dispensa a participação ativa de sua própria população, sob pena de estar fadada ao fracasso, em especial, a população nativa (indígena ou não) (CASTRO, 2019).

É notório que qualquer tentativa de definir a Amazônia é incipiente, pois o cenário ambiental que se construíra com palavras é inegavelmente menor que o próprio significado que tem esse bioma para nosso país e planeta. Todavia, vale a pena tentar realizar esta tarefa apenas para contextualizar o leitor na grandeza desse patrimônio ambiental:

\begin{abstract}
A Amazônia é um mosaico de múltiplos fatores e interesses. Ela inclui mais sete países, Bolívia, Equador, Colômbia, Guiana, Peru, Suriname e Venezuela, que, aos 3 de julho de 1978, celebraram o Tratado de Cooperação Amazônica, cujos resultados são desconhecidos.

Mas, é no território brasileiro que a Amazônia ocupa maior espaço, nada menos do que 5.500.000 quilômetros, sendo a maior floresta tropical do mundo. Sua importância no equilíbrio do meio ambiente extrapola nossas fronteiras.

No Ibama, segundo consta, em 2019 o órgão solicitou 2.054 vagas, sendo 847 para técnico administrativo, 313 para analista administrativo e 894 para analista ambiental, porém o pedido não foi autorizado. $\mathrm{O}$ concurso aberto neste ano para contratar funcionário temporários em situações de emergência foi suspenso. No órgão estadual amazonense, Instituto de Proteção Ambiental do Amazonas (Ipaam), o site de transparência revela a existência de pouco mais de 200 funcionários, número insuficiente que mal deve dar para atender a capital, Manaus.

O resultado desta soma de fatores é de todos conhecido. Segundo o Instituto Nacional de Pesquisas Espaciais (Inpe), a Amazônia tem o $14^{\circ}$ mês seguido de alta de desmatamento sendo que só no mês de junho mais de 1.000 quilômetros quadrados foram destruídos (FREITAS, 2021).
\end{abstract}

Não obstante, cediço é que a proteção jurídica ao meio ambiente possui um marco histórico relevante: a Conferência de Estocolmo de 1972, pois foi nesse encontro de representantes de diversas nações que discutiram a questão ambiental, tornando o tema uma preocupação mundial (TRENNEPOHL, 2019). No entanto, esta preocupação não nasceu no deserto, mas de alguns desastres ecológicos ocorridos após a Segunda Guerra Mundial, conforme expõe Rodrigues (2005, p. 118):

\footnotetext{
Alguns desastres ecológicos, causados por poluição industrial, tal como o de Donora, na Pensilvânia, em 1948, provocado pela indústria siderúrgica, que afetou $47 \%$ da população local. Também em Londres, em 1952, mais de 4 mil mortes foram registradas em decorrência da ocorrência do fenômeno de "inversão térmica" que impediu que os gases oriundos da queima do carvão para aquecimento das casas, dos veículos e das empresas fossem naturalmente dissipados. Isso fez com que esses gases ficassem concentrados, fazendo com que a população fosse asfixiada pelos mesmos.
} 
Neste cenário, conforme exposto alhures neste projeto, o legislador brasileiro também passou a demonstrar uma maior preocupação com o tema que culminou, ainda na década de 80, com a edição da Lei nº 6.938/1981 (Lei da Política Nacional do Meio Ambiente).

Posteriormente, a própria Constituição de 1988 trouxe previsão específica deste direito no artigo 225: “Art. 225. Todos têm direito ao meio ambiente ecologicamente equilibrado, bem de uso comum do povo e essencial à sadia qualidade de vida, impondo-se ao Poder Público e à coletividade o dever de defendê-lo e preservá-lo para as presentes e futuras gerações" (BRASIL, 1988).

Não obstante, a preocupação com o meio ambiente no campo jurídico já poderia encontrar proteção jurídica no meio jurídico com fundamento no direito à saúde ou no regramento da produção e consumo, conforme leciona Benjamin (2002, p. 98-99):

\footnotetext{
Realmente, a lacuna nas ordens constitucionais anteriores a 1988 não foi sério óbice à regulamentação legal de controle das atividades nocivas ao ambiente, ou, mais comum, aos seus elementos. Faltando uma base incontroversa de apoio na Constituição, o legislador ordinário foi buscar suporte ora na proteção da saúde (sob o argumento de que ela não pode ser assegurada em ambiente degradado), ora no regramento da produção e consumo.
}

Dias (2003, p. 120), por sua vez, arremata a relevância quando assevera que o "direito ao meio ambiente equilibrado e sadio é um instrumento de garantia à vida e nesse sentido, é difuso, independentemente de sua feição jurídica ou mesmo de seu possível enquadramento em um esquema intelectivo".

Nesse prisma, a tutela, provisória ou definitiva, do meio ambiente perpassa por compreender suas características: a indeterminação de seus sujeitos, a indivisibilidade dos interesses difusos tutelados e a própria conflituosidade oculta entre os atores sociais envolvidos.

Explicando, por sua vez, estas características do meio ambiente. Tem-se que a indeterminação dos sujeitos significa que todos os membros da sociedade têm difusamente "o direito de exigir que a ação estatal e privada seja no sentido de assegurar aquele direito" (DIAS, 2003, p. 119). A indivisibilidade, por sua vez, pode ser observada na impossibilidade de fracionamento do direito entre os membros que compõem a coletividade (TARTUCE e NEVES, 2017). 
Certamente, a conflituosidade pode ser observada no choque de pontos de vista existente no próprio interior deste ramo do direito, no qual se discute aspectos como a utilidade, a necessidade e a própria efetividade dos valores envolvidos e discutidos nas demandas ambientais (DIAS, 2003, p. 120).

No âmbito do Direito Ambiental, dois princípios são relevantes para compreensão desse ramo do direito: a prevenção e a precaução. A doutrina trata estes princípios de forma muito semelhante, porém Rodrigues (2005) expõe que a precaução é mais abrangente que a prevenção. A primeira encontraria terreno quando houvesse dúvida sobre a questão, ou seja, em momentos em que as consequências são ainda desconhecidas, há que se tomar cuidado, impedindo eventuais ações humanas desastrosas.

De outro lado, a prevenção pode ser entendida como o fato de que o dano ambiental costuma ser de difícil reparação ou praticamente impossível. Logo, é melhor prevenir a ocorrência do dano ambiental a permitir sua ocorrência, valendo aquela máxima popular: é melhor prevenir do que remediar (RODRIGUES, 2005).

Do mesmo modo, Machado (2005, p. 72) arremata:

\begin{abstract}
Há certeza científica ou há incerteza científica do risco ambiental? Há ou não unanimidade no posicionamento dos especialistas? Devem, portanto, ser inventariadas as opiniões nacionais e estrangeiras sobre a matéria. Chegou-se a uma posição de certeza de que não há perigo ambiental? A existência de certeza necessita ser demonstrada, porque vai afastar uma fase de avaliação posterior. Em caso de certeza do dano ambiental, este deve ser prevenido, como preconiza o princípio da prevenção. Em caso de dúvida ou de incerteza, também se deve agir prevenindo. Essa é a grande inovação do princípio da precaução. A dúvida científica, expressa com argumentos razoáveis, não dispensa a prevenção. "O princípio da precaução consiste em dizer que não somente somos responsáveis sobre o que nós sabemos, sobre o que nós deveríamos Ter sabido, mas, também, sobre o de que nós deveríamos duvidar" - assinala o jurista Jean - Marc Lavieille. Aplica-se o princípio da precaução ainda quando existe a incerteza, não se aguardando que esta se torne certeza.
\end{abstract}

Com efeito, o meio ambiente deve ser protegido mesmo que haja dúvida sobre a necessidade de tal proteção ambiental. Tais princípios só reforçam a relevância do direito a um meio ambiente equilibrado, aplicando a posição clássica de Canotilho (2000) quando considera fundamental um direito humano que alcançou o nível constitucional e, por isso, permite que este seja oponível a qualquer autoridade ou mesmo aos agentes privados.

Feitas tais considerações, já se mostra possível a análise do caso concreto proposto pelo presente artigo: a ADPF $\mathrm{n}^{\circ}$ 709/DF (BRASIL, 2021). 


\title{
4 UMA BREVE ANÁLISE DA LIMINAR CONCEDIDA NA ADPF 709/DF E SEUS EFEITOS PRÁTICOS PARA PROTEÇÃO DO MEIO AMBIENTE E DAS TERRAS INDÍGENAS YANOMAMI E MUNDURUKU
}

Partindo-se para análise da ADPF no 709/DF, tem-se, na liminar deferida pelo Ministro Luís Roberto Barroso, bem presente os elementos da tutela provisória expostos acima no presente artigo, como se verifica, a seguir:

\begin{abstract}
Ementa: DIREITOS FUNDAMENTAIS. POVOS INDÍGENAS. ARGUIÇÃO DE DESCUMPRIMENTO DE PRECEITO FUNDAMENTAL. TUTELA PROVISÓRIA INCIDENTAL. CONFLITOS VIOLENTOS, PRESENÇA DE INVASORES, GARIMPO ILEGAL E CONTÁGIO POR COVID-19 NAS TIS YANOMAMI E MUNDURUCU. 1. Os requerentes da presente ADPF e nove outras entidades que atuam no feito como amici curiae relatam ataques a tiros a indígenas, mortes, desnutrição, anemia, contágio por mercúrio, desmatamento e garimpo ilegal, bem como a prática de ilícitos de toda ordem decorrentes da presença de invasores nas Terras Indígenas Yanomami e Mundurucu, no curso da pandemia. Afirmam que tal presença é responsável ainda pelo contágio de tais comunidades por COVID-19. À luz de tal quadro, pedem deferimento de tutela provisória incidental para assegurar a vida, a saúde e a segurança de tais povos no contexto da crise sanitária. 2. Verossimilhança do direito e perigo na demora configurados. Incidência dos princípios da precaução e da prevenção, conforme jurisprudência consolidada do Supremo Tribunal Federal. Nesse sentido: ADI 5592, Rel. p/ acórdão Min. Edson Fachin; ADI 4066, Rel. Min. Rosa Weber; RE 627189, Rel. Min. Dias Toffoli. 3. Cautelar parcialmente deferida, para adoção imediata de todas as medidas necessárias à proteção da vida, da saúde e da segurança da população indígena que habita as TIs Yanomami e Mundurucu (BRASIL, 2021).
\end{abstract}

Basicamente, os fatos narrados relatam uma suposta invasão nas Terras Indígenas Yanomami e Mundurucu. Tais invasores visavam a exploração econômica das áreas invadidas com atividades como mineração e extração de madeira. Ademais, esta situação estaria aumentando o risco de contágio da população indígena por COVID-19.

Em sua decisão liminar, o Ministro Luís Roberto Barroso abre um tópico de sua decisão para contextualizá-la num ambiente de falta de transparência da União e de "atos protelatórios de toda ordem quanto ao atendimento de saúde e vacinação de povos indígenas", a fim de demonstrar a inércia do Estado como um dos fatores de acirramento da gravidade da situação existente, o que só reforça o esta realidade como um dos elementos para o atendimento do requisito da tutela provisória conhecido como "periculum in mora" na decisão do Ministro (BRASIL, 2021). 
Feitas tais ponderações introdutórias, cabe a análise da decisão liminar e como esta se enquadrou nos requisitos do instituto da tutela provisória.

Primeiramente, observa-se que a probabilidade do direito encontra fundamento no seguinte trecho da decisão:

\begin{abstract}
Assiste razão, ainda, aos requerentes no sentido de que, diante de tais indícios e do risco de contágio e morte, a decisão proferida neste feito deve se basear nos princípios constitucionais da prevenção e da precaução, conforme jurisprudência consolidada nesta Corte. Nesse sentido: ADI 5592, Rel. p/ acórdão Min. Edson Fachin; ADI 4066, Rel. Min. Rosa Weber; RE 627189, Rel. Min. Dias Toffoli. De fato, ainda que pudesse haver qualquer dúvida sobre a ameaça aos bens e direitos já aludidos, os elementos apresentados são suficientes para recomendar que se adotem medidas voltadas à proteção de tais povos (BRASIL, 2021).
\end{abstract}

No trecho acima, observa-se que a decisão não se imiscui em detalhes ou exige um lastro probatório robusto para sua prolação. Basicamente, o Ministro apresenta os princípios da prevenção e da precaução como suficientes para atender ao requisito da tutela provisória da probabilidade do direito (“fumus boni iuris”). Deveras, aplica-se o entendimento de que, num juízo de cognição superficial típico de tutelas provisórias, a existência de questões ambientais atrai os princípios que regem o tema, em especial, os da prevenção e da precaução, os quais relativizam a exigência deste requisito para concessão da tutela provisória, ${ }^{4}$ a fim de proteger o meio ambiente natural e cultural (comunidades indígenas Yanomami e Mundurucu) supostamente ameaçados.

Prosseguindo com a análise do julgado, tem-se o trecho em que se mostra o fundamento da decisão no que tange ao requisito do perigo de dano ("periculum in mora"):

\begin{abstract}
Além disso, o risco à vida, à saúde e à segurança de tais povos se agrava ante a recalcitrância e a falta de transparência que tem marcado a ação da União neste feito, o que obviamente não diz respeito a todas as autoridades que oficiam no processo, muitas das quais têm empenhado seus melhores esforços, mas diz respeito a algumas delas, suficientes para comprometer o atendimento a tais povos. Não há dúvida, ademais, do evidente perigo na demora, dado que todo tempo transcorrido pode ser fatal e implicar conflitos, mortes ou contágio (BRASIL, 2021).
\end{abstract}

Novamente, tem-se uma fundamentação concisa, na qual apenas se aponta os elementos existentes ao longo do texto como suficientes para demonstrar que o perigo da

\footnotetext{
${ }^{4}$ Poder-se-ia, também, analisar a presente decisão sob o prisma do artigo 489, do Código de Processo Civil (CPC). Todavia, isto fugiria ao objeto do presente artigo, podendo ser objeto de outro estudo futuro.
} 
demora na prestação daquela tutela jurisdicional poderia representar a perda de diversas vidas dos povos indígenas.

Não há também no voto do ministro qualquer análise sobre a irreversibilidade da medida.

No entanto, para fins deste artigo, observa-se como a questão ambiental permitiu e exigiu uma atuação do Poder Judiciário célere, sob pena de se tornar inócua e comprometer a construção de um processo civil de resultados pacificadores e asseguradores do acesso à justiça.

Sobre o assunto, tem-se a importante lição de Bedaque (2007, p. 18):

\begin{abstract}
As regras processuais existem para assegurar o bom desenvolvimento do procedimento e o real equilíbrio entre os sujeitos parciais dessa relação jurídica, para o quê também é fundamental a efetiva participação do juiz. A regulamentação desse método de solução de conflitos chamado 'processo' destina-se a possibilitar que o resultado da atividade estatal contribua decisivamente para a manutenção da integridade do ordenamento jurídico, a eliminação dos litígios e a pacificação social.
\end{abstract}

Do mesmo modo, foi a posição do Supremo Tribunal Federal (STF) em outros julgados, inclusive, mencionados no trecho da decisão acima: ADI 5592, Rel. p/ acórdão Min. Edson Fachin; ADI 4066, Rel. Min. Rosa Weber; e RE 627189, Rel. Min. Dias Toffoli.

Enfim, Dinamarco (2020) e Carvalho (2015) asseveram que a atividade jurisdicional eficiente deve gerar um processo civil de "resultados". In casu, o Ministro Luís Roberto Barroso defere tal pleito liminar, justamente, para que, quando for ocorrer o julgamento propriamente dito da demanda, a decisão final não seja mais despicienda, tendo em vista a consolidação fática de uma situação supostamente iníqua e avessa ao meio ambiente natural e cultural das comunidades indígenas Yanomami e Mundurucu na Amazônia brasileira.

\title{
5 CONSIDERAÇÕES FINAIS
}

O processo é algo que possui um tempo de maturação para sua formação e finalização. Infelizmente, o direito fundamental a um meio ambiente equilibrado não 
permite muitas vezes que se aguarde tanto e exige uma atuação estatal urgente, a fim de protegê-lo com eficiência.

Nesse sentido, o instituto da tutela provisória amolda-se perfeitamente as necessidades e peculiaridades da seara ambiental. Para demonstrar este argumento, esperase que ao longo desse artigo tenha sido analisado satisfatoriamente os seguintes tópicos:

a) $\mathrm{O}$ instituto da tutela possui como finalidade abrandar os males do tempo e assegurar uma tutela jurisdicional efetiva. Trata-se, em poucas palavras, de equilibrar os efeitos do tempo de tramitação do processo para as partes, resguardando, na medida do possível, que o direito seja protegido e/ou que uma situação irregular prossiga no tempo antes da prolação da decisão judicial final por parte do Poder Judiciário.

b) Um meio ambiente equilibrado é um direito fundamental previsto na Constituição de 1988, que tem como norteadores dois princípios do Direito Ambiental: precaução e prevenção.

c) Os princípios da precaução e da prevenção são basilares na seara ambiental, servindo como fundamento de decisões administrativas e judiciais que envolvam a matéria, ainda, que em sede de cognição judicial sumária típica de tutelas provisórias.

d) A ADPF 709/DF utilizou em sua fundamentação para atender aos requisitos da tutela provisória, em especial, o da probabilidade do direito, o argumento de que a precaução e a prevenção conduzem o julgador a uma postura protetiva, a fim de evitar danos irreversíveis ao meio ambiente e às populações indígenas envolvidas.

Esta linha de atuação do Supremo Tribunal Federal (STF) vai ao encontro de outros julgados já mencionado alhures, bem como ao que fora defendido pelo Ministro Luiz Fux, atual presidente daquela Corte, em recente artigo, intitulado "Justiça Infectada? A hora da prudência", no qual expõe que a pandemia exige uma "prudência redobrada" antes de intervir em cenários “complexos, incalculáveis ou imprevisíveis” (FUX, 2020). ${ }^{5}$

\footnotetext{
5 “Antes de decidirem, devem os juízes ouvir os técnicos, porque uma postura judicial diversa gera decisões passionais que desorganizam o sistema de saúde, gerando decisões trágicas e caridade injusta. A novel figura do amigo da Corte (amicus curiae), que pode ser um cientista, um economista, um médico, foi incorporada ao novo Código de Processo Civil para coadjuvar os juízes e tribunais nas decisões que exigem conhecimentos que escapam à formação dos profissionais do Direito. A participação desses experts é fundamental, na medida em que aqui e ali vislumbram-se decisões que apreendem máscaras e remédios, internam-se pessoas cujo tratamento deve ser caseiro, fadigando a disponibilidade de leitos hospitalares, impede-se a criação de postos próximos aos cidadãos para receberem o auxílio econômico governamental, entre outras. Positivamente, não é hora do impulso imoderado, mas do raciocínio prudente, racional e consequencialista, sob pena de a Justiça, cujo [sic] desígnio é dar a cada um o que é seu, transformar-se num paciente infectado por uma
} 
Enfim, em matéria ambiental, esta prudência foi compreendida sob as lentes dos princípios ambientais da prevenção e da precaução no caso da ADPF no 709/DF, o que apenas reforça a importância de se repensar o meio ambiente no Estado Democrático Brasileiro. Indubitavelmente, o meio ambiente se apresenta como um cenário complexo e imprevisível que deve ser protegido esteja ou não o mundo vivenciando um cenário de pandemia. Logo, os cuidados exigidos de qualquer juiz ao analisar uma demanda ambiental parecem ser os mesmos, ou seja, de precaução ao se imiscuir na matéria, em grande parte, desconhecida pela Ciência humana, devendo na dúvida proteger de imediato aquele direito fundamental a um meio ambiente equilibrado, relativizando o requisito da "probabilidade do direito" e valendo-se do instrumento processual da tutela provisória na busca de um processo civil de "resultados", sob pena gerar danos ambientais irreversíveis para toda coletividade e despicienda a demanda processual ajuizada perante o Poder Judiciário.

\section{REFERÊNCIAS}

BEDAQUE, José Roberto dos Santos. Efetividade do processo e técnica processual. 2. ed. São Paulo: Malheiros, 2007.

BENJAMIN, Antônio Herman. "Meio ambiente e Constituição: uma primeira abordagem". Congresso Internacional de Direito Ambiental. ANAIS do $6^{\circ}$ Congresso Internacional de Direito Ambiental, de 03 a 06 de junho de 2002: 10 Anos da ECO-92: O Direito e o Desenvolvimento Sustentável. São Paulo: IMESP, 2002.

BRASIL. Constituicão da República Federativa do Brasil de 1988. Disponível em: http://www.planalto.gov.br/ccivil_03/constituicao/constituicao.htm Acesso em: 20 jul. 2021.

Lei n ${ }^{0} 5.869$, de 11 de janeiro de 1973. Institui o Código de Processo Civil. Disponível em: http://www.planalto.gov.br/ccivil 03/leis/15869impressao.htm Acesso em: 20 set. 2021.

Lei n ${ }^{0} 6.938$, de 31 de agosto de 1981. Dispõe sobre a Política Nacional do Meio Ambiente, seus fins e mecanismos de formulação e aplicação, e dá outras providências. Disponível em: http://www.planalto.gov.br/ccivil 03/leis/16938.htm Acesso em: 20 set. 2021.

Covid que adoece a alma e a razão, ferindo de morte, a um só tempo, a vida dos que sofrem e a esperança dos que intentam viver" (FUX, 2020, grifo nosso). 
Lei $\mathbf{n}^{0}$ 10.257, de 10 de julho de 2001. Regulamenta os arts. 182 e 183 da Constituição Federal, estabelece diretrizes gerais da política urbana e dá outras providências. Disponível http://www.planalto.gov.br/ccivil_03/leis/leis_2001/110257.htm Acesso em: 20 set. 2021.

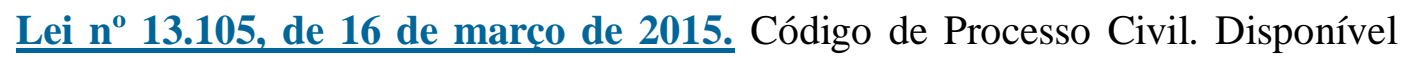
em: http://www.planalto.gov.br/ccivil 03/ ato2015-2018/2015/lei/113105.htm Acesso em: 20 set. 2021.

STF. ADI 3.540 MC/DF, rel. Min. Celso de Mello, Tribunal Pleno, DJ 3-2-2006.

. STF. ADPF no 709/DF, Relator Ministro Luís Roberto Barroso, j. 24.05.2021. Disponível em: http://www.stf.jus.br/arquivo/cms/noticiaNoticiaStf/anexo/ADI6341.pdf Acesso em: 20 jul. 2021.

. Operação Verde Brasil aplica cerca de R 142 milhões em multas e combate 1.835 focos de incêndio. Verde Brasil, 29 out. 2019. Disponível em: https://www.gov.br/ptbr/noticias/meio-ambiente-e-clima/2019/10/operacao-verde-brasil-aplica-cerca-de-r-142milhoes-em-multas-e-combate-1-835-focos-de-incendio. Acesso em: 20 set. 2021.

BRITO FILHO, José Cláudio Monteiro de. Justiça: temas de liberalismo igualitário. Brasília, DF: Editora Venturoli, 2021.

CÂMARA, Alexandre Freitas. O novo processo civil brasileiro. São Paulo: Atlas, 2015.

CAnOtilho, J.J. Gomes. Direito Constitucional e Teoria da Constituição. CoimbraPortugal: Almedina, 2000.

CARVALHO, Fabiano. O princípio da eficiência no processo coletivo. IN: MILARÉ, Édis. A ação civil pública após 30 anos. São Paulo: Revista dos tribunais, 2015.

CASTRO, Edna. Estratégias de expansão territorial de empresas minerais na Amazônia, desastres socioambientais e "zonas de sacrifício". In: CASTRO, Edna Ramos de; CARMO, Eunápio Dutra do. Dossiê desastres e crimes da mineração em Barcarena. Belém: NAEA-UFPA, 2019.

DIAS, Jean Carlos. Políticas Públicas e Questão Ambiental. Revista de Direito Ambiental, v. 31, p. 117-135, 2003.

DIDIER JR. Fredie; BRAGA, Paulo Sarno; OLIVEIRA, Rafael Alexandria de. Curso de Direito Processual Civil: Teoria da Prova, Direito Probatório, Decisão, Precedente, Coisa Julgada, Processo Estrutural e Tutela Provisória. 10. ed. Salvador: Editora Juspodivm, 2015.

DINAMARCO, Candido Rangel. Instituições de direito processual civil. 10. ed. rev. e atual. segundo o Código de Processo Civil e de acordo com a Lei n. 13.256, 4.2.2016. São Paulo: Malheiros, 2020, v. 1. 
FREITAS, Vladimir Passos de. Amazônia e seus defeitos na proteção do meio ambiente. In: Revista Consultor Jurídico, 19 de julho de 2020. Disponível em: https://www.conjur.com.br/2020-jul-19/amazonia-desafios-protecao-meioambiente?imprimir=1. Acesso em: 20 set. 2021.

FUX, Luiz. Justiça infectada? A hora da prudência. Se exige-se do homem médio ouvir e respeitar a Ciência, com mais razão assim devem proceder os magistrados. O Globo, 30 mar. 2020. Disponível em: https://oglobo.globo.com/opiniao/artigo-justica-infectada-horada-prudencia-24337119? Acesso em: 20 set. 2021.

IMAZON. Instituto do Homem e Meio Ambiente da Amazônia. Disponível em: https://imazon.org.br/imprensa/desmatamento-chega-a-810-km\%c2\%b2-na-amazonialegal-em-marco-de-2021-aponta-imazon/_Acesso em: 20 set. 2021.

JORGE NETO, Nagibe de Melo. Abrindo a caixa preta: por que a Justiça não funciona no Brasil. 2. ed. rev., atual. e ampl. Salvador: Editora Juspodivm, 2018.

LEAL, Rogério Gesta. As múltiplas dimensões da relação entre Economia e Direito (capítulo segundo). In: LEAL, Rogério Gesta. Impactos econômicos e sociais das decisões judiciais: Aspectos introdutórios. Brasília: ENFAM, 2010, p. 35-82.

MACHADO, Paulo Affonso Leme. Direito Ambiental Brasileiro. São Paulo: Malheiros Editores, 2005.

MARINONI, Luiz Guilherme. Tutela provisória. São Paulo: Editora Revista dos Tribunais, 2017.

; ARENHART, Sérgio Cruz; MITIDIERO, Daniel. Novo curso de processo civil: tutela dos direitos mediante procedimento comum. 3. ed. São Paulo: Editora Revista dos Tribunais, 2017, v. 2.

MILARÉ, Édis. Direito do ambiente: doutrina, prática, jurisprudência, glossário. 2 ed. rev. atual. e ampl. São Paulo: Editora Revista dos Tribunais, 2001.

MOUTA, José Henrique. As tutelas provisórias e a judicialização da crise decorrente da COVID/19. Revista Migalhas, 22 jun. 2021. Disponível em:

https://www.migalhas.com.br/depeso/347406/a-tutela-provisoria-e-a-judicializacao-dacrise-decorrente-da-covid-19 Acesso em: 25 jul. 2021.

PINHO, Humberto Dalla Bernardina. Manual de direito processual civil contemporâneo. 2. ed. São Paulo: Saraiva, 2020.

RODRIGUES, Marcelo Abelha. Elementos de Direito Ambiental: parte geral. 2. ed. São Paulo: Editora Revista dos Tribunais, 2005.

SECCHI, Leonardo. Políticas públicas: conceitos, esquemas de análise, casos práticos. São Paulo: Cengage Learnig, 2016. 
SILVA, José Afonso da. Curso de direito Constitucional Positivo. 29. ed. São Paulo: Malheiros, 2007.

TARTUCE, Flávio; NEVES, Daniel Amorim Assumpção. Manual de direito do consumidor: direito material e processual. 6. ed. rev. e atual. Rio de Janeiro: Método, 2017.

TRENNEPOHL, Terence. Manual de direito ambiental. 7. ed. São Paulo: Saraiva Educação, 2019.

WALKER, Robert et al. A expansão da agricultura intensiva e pecuária na Amazônia Brasileira. Amazonia and Global Change. Geophysical Monograph Series 186, 2009. Disponível em:

https://daac.ornl.gov/LBA/lbaconferencia/amazonia global change/5 A\%20Expansao Ag ricultura_Walker.pdf. Acesso em: 25 jul. 2021. 